\title{
ERRATUM
}

\section{Breast cancer and long-term hormonal treatment of male hypogonadism}

\author{
Marek Medras · Alicja Filus · Paweł Jozkow • \\ Jacek Winowski $\cdot$ Teresa Sicinska-Werner
}

Published online: 30 January 2007

(C) Springer Science+Business Media B.V. 2007

Erratum to: Breast Cancer Res Treat

DOI 10.1007/s10549-005-9074-y

Unfortunately the author names appear incorrectly in the article. The correct author names are:

Marek Medras, Alicja Filus, Paweł Jozkow, Jacek Winowski, Teresa Sicinska-Werner

The online version of the original article can be found at http:// dx.doi.org/10.1007/s10549-005-9074-y

M. Medras · A. Filus

Department of Endocrinology, Diabetology and Nuclear

Therapy, Wroclaw Medical University, Wroclaw, Poland

P. Jozkow $(\bowtie)$

Department of Sports Medicine, University School of

Physical Education, Wroclaw, Poland

e-mail: pjozkow@wp.pl

J. Winowski

Second Department of General and Oncological Surgery,

Wroclaw Medical University, Wroclaw, Poland

T. Sicinska-Werner

Endocrinology Outpatient Clinic, Regional Medical Center,

Opole, Poland 